\title{
Teologia e direitos humanos: reflexões a partir do pensamento de Giorgio Agamben
}

\author{
Theology and human rights: reflections from \\ the thinking of Giorgio Agamben
}

\section{Osiel Lourenço Carvalho*}

Faculdade Refidim, Joinvile, SC, Brasil

\section{Resumo}

O presente artigo discutirá as intersecções entre teologia e direitos humanos no Estado moderno a partir do pensamento do filósofo italiano Giorgio Agamben, que propõe uma discussão daquilo que chamou de genealogia teológica das teorias democráticas na contemporaneidade. Agamben recorre principalmente a categorias teológicas e míticas cristãs do período medieval e analisa a presença delas nas estruturas governamentais e no poder soberano da modernidade. Para tratar dos paradigmas teológicos, Agamben dialoga com Carl Schmitt, para quem as doutrinas que constituem o estado moderno são conceitos teológicos secularizados. Ao contrário do que disse Max Weber, o desencantamento do mundo não gerou uma desteologização na modernidade, pois mesmo que esteja no subterrâneo das ideias políticas, a teologia ainda prossegue atuante no mundo com impactos no campo do biopoder e dos direitos humanos.

Palavras-chave: Estado moderno. Teologia. Direitos humanos. Biopolítica.

*OLC: Doutor em Ciências da Religião, e-mail: osiel_carvalho@yahoo.com.br 


\section{Abstract}

This article will discuss the intersections between theology and human rights in the modern state from the thought of the Italian philosopher Giorgio Agamben proposes a discussion of what he called the theological genealogy of democratic theories in contemporary times. Agamben refers primarily to the theological and mythical Christian categories of the medieval period and analyzes their presence in governmental structures and the sovereign power of modernity. To deal with the theological paradigms Agamben, he dialogues with Carl Schmitt, for whom the doctrines that constitute the modern state are secularized theological concepts. Contrary to Max Weber's contention, the disenchantment of the world has not led to a de-modernization in modernity, for even if it is in the underground of political ideas, theology still continues to operate in the world with impacts on biopower and human rights.

Keywords: Modern state. Theology. Human rights. Biopolitics.

\section{Introdução}

O presente artigo tem como finalidade apresentar o pensamento de Giorgio Agamben sobre as origens teológicas do estado moderno e em que medida o ordenamento jurídico-político da modernidade afeta o discurso de direitos humanos. Metodologicamente, iremos refletir sobre importantes obras do filósofo italiano como O Reino e a Glória e Homo Sacer: O poder soberano e a vida nua. Dentre nossos objetivos está o de analisar se o discurso de direitos humanos das sociedades liberaiscapitalistas serviram para fortalecer o biopoder do Estado moderno.

Giorgio Agamben em $O$ Reino e a Glória faz uma genealogia teológica do poder. Para ele, o poder assumiu a forma de uma "economia". Em sua análise, Agamben discute a oikonomia com pais da Igreja como Tertuliano, Irineu, Santo Agostino e Tomas de Aquino. Nos primeiros séculos o cristianismo procurou conciliar o monoteísmo com a doutrina da Trindade (Pai, Filho e Espírito Santo) e, a partir daí, se discutiu a oikonomia que está relacionada ao governo dos homens e das coisas. Para 
Agamben, esse paradigma teológico-econômico se fundiu com a doutrina da providência divina. Esses imaginários teológicos teriam sido assumidos pela máquina de governo do Ocidente, configurando, assim, a concepção de um Estado-providência. Todavia, esse governo não é apenas poder, mas ele é também glória. Desse modo, há marcas e insígnias teológicas no Estado moderno. Para fundamentar sua discussão Agamben propõe uma genealogia teológica do poder.

Importante interlocutor de Agamben em sua genealogia teológica será Michel Foucault. Para ambos a modernidade rompeu a lógica da soberania divina que controlava os corpos, de modo que o Estado assumiu a prerrogativa da decisão sobre a vida dos indivíduos e de domínio da vida. Essa função do Estado pode ser percebida nos textos do Contrato Social de Rousseau, tendo em vista que ao discutir o seu papel ele afirma que "a transição do estado natural ao civil produz no homem mudança notável, substituindo em sua conduta a justiça do instinto e dando aos seus atos a moralidade de que antes careciam" (ROSSEAU, 2011, p. 33). Com base no fundamento da dignidade humana, o Estado no Ocidente se tornou o garantidor dos direitos do cidadão. Entretanto, essa categoria "cidadão" remete também aos deveres, desse modo os membros da sociedade devem se sujeitar ao poder decisório do Estado. Nesse cenário, a política se tornou biopolítica. O sistema de governo nas democracias modernas "hibridiza" estruturas públicas e privadas a fim de regulamentar e governar a vida.

\section{Arqueo-genealogia teológica do Estado moderno}

Giorgio Agamben discute a respeito de uma genealogia teológica das teorias democráticas na contemporaneidade. Agamben recorre principalmente a categorias teológicas e místicas do período medieval e analisa a presença delas nas estruturas governamentais. Um exemplo disso é a doutrina da Trindade, que enquanto dimensão do sagrado assumiu novas formas como foi a separação dos três poderes em: executivo, legislativo e judiciário. Além disso, expressões litúrgicas e simbologias do poder estão presentes na política. De modo inicial, apresentaremos as reflexões de Agamben em $O$ Reino e a Glória, articuladas com o 
funcionamento das técnicas de governo dos Estados-nação. Veremos que, para Agamben o governo é poder e glória. Sendo assim, as categorias teológicas nos ajudam não apenas a entender as teorias democráticas da contemporaneidade, mas também avaliá-las e profaná-las.

\section{Paradigma teológico e econômico}

Agamben propõe a genealogia de um paradigma que exerceu influência sobre o ordenamento da sociedade global. De acordo com o filósofo italiano, dois paradigmas políticos são derivados da teologia cristã: (i) a teologia política, em cujo fundamento está Deus em sua soberania e transcendência; (ii) a teologia econômica, que substitui a ideia da oikonomia (gestão, governo das coisas). "Do primeiro paradigma derivam a filosofia política e a teoria moderna da soberania; do segundo, a biopolítica moderna até o atual triunfo da economia e do governo sobre qualquer outro aspecto da vida social" (AGAMBEN, 2012, p. 13). No cristianismo primitivo, Eusébio de Cesaréia estabeleceu uma relação entre o aparecimento de Jesus, o imperador romano Augusto e, posteriormente Constantino. Sendo que, a partir daí a noção de poliarquia pluralista deu lugar a uma monarquia política, com bases numa monarquia divina; nesse governo soberano, seu poder é divinamente legitimado.

Para tratar desses paradigmas, Agamben busca fundamentação em Carl Schmitt, para quem as doutrinas que constituem o Estado moderno são conceitos teológicos secularizados. Ao contrário do que disse Max Weber, o desencantamento do mundo não gerou uma desteologização dos processos sociais, pois mesmo que esteja no subterrâneo das ideias políticas, a teologia ainda prossegue atuante no mundo. Sendo assim, tanto as esferas políticas como as econômicas teriam em sua estrutura e funcionalidade paradigmas teológicos. Walter Benjamin (2013, p. 128) - assim como Franz Hinkelammert (2012, p. 172) - fizeram análises semelhantes na medida em que o capitalismo também estaria fundamentado a partir de conceitos teológicos e, em razão disso, poderíamos classificá-lo como uma religião. 
Quando o Estado moderno exclui as justificativas teológicas da soberania, o poder precisou encontrar outras instâncias, para além da transcendência na qual pudesse fundamentar sua legitimação. Essa ruptura gerou guerras, levantes populares e revoluções a fim de instaurar uma nova ordem política em que a soberania divina teria sido substituída pela soberania dos Estados nacionais. Era como se houvesse uma nova criação ex nihilo de uma nova ordem secular (CATROGA, 2006).

Fundamental no texto de Agamben é o termo oikonomia, de modo que o filósofo retoma os escritos de Padres da Igreja como Tertuliano, Hipólito, Irineu e Clemente, a fim de substanciar sua tese de que o referido termo esteve relacionado com a "gestão", "atividade divina", "administração da casa”, "governo", realizadas por intermédio de uma economia da trindade. Todavia, para a doutrina da oikonomia, o governo de Deus no mundo não é de natureza ontológica, mas prática; pensamento contrário ao de Aristóteles, por exemplo, para quem o motor imóvel que controla as esferas celestes está circunscrito numa relação de harmonia entre o ser e práxis. Quando os pais da Igreja discutiram a doutrina da oikonomia, quiseram evitar o surgimento da pluralidade de divindades e, por conseguinte o politeísmo, de modo que "a simples disposição da economia não significa de modo algum a separação da substância. O ser divino não é dividido porque a triplicidade de que falam os Padres se situa no plano da oikonomia, e não naquele da ontologia" (AGAMBEN, 2012, p. 67). Portanto, a vontade livre de Deus, distinta de sua natureza, tornou-se um elemento central na teologia cristã; essa dissociação entre o ser e práxis, principalmente após o Concílio de Nicéia, gerou uma "cristologia anárquica".

A oikonomia teológica é a matriz da oikonomia na modernidade, pois as duas estão relacionadas com o governo da vida humana. Durante os primeiros séculos da teologia cristã a oikonomia como administração da vida também se vinculou às questões sobre a liberdade humana e o plano de Deus. Desse modo, se inquiriu as possibilidades de harmonizar a obra salvífica divina e a liberdade humana. A economia moderna derivou do paradigma da questão de como se deve governar as populações e ao mesmo tempo respeitar seus desejos. O resultado disso foi o surgimento da economia política, que preservou os princípios da teologia econômica 
de governo no mundo de Deus pelo Estado ou mercado. Com efeito, na economia política da modernidade é preciso saber administrar a vontade das outras pessoas e dirigi-la a objetivos previamente estabelecidos.

Para Agamben, a economia política moderna se apropriou da noção de providência divina - e traduziu isso na forma de técnicas de governo - a fim de harmonizar desejos humanos com as políticas voltadas ao controle das populações. "O resultado deste deslocamento foi a produção em grande escala de táticas utilitárias de fabricação de desejos, controle de condutas, normalização de comportamentos, padronização de subjetividades" (RUIZ, 2015, p. 27). Desse modo, a economia se tornou o governo da vida.

Assim como Hannah Arendt, Agamben discute vida a partir de dois conceitos pensados pelos gregos: zoé e bíos. A zoé é a vida biológica, como aquela compartilhada pelas plantas, animais e seres humanos. Ela está sujeita às leis da natureza, de modo que a vontade humana precisa estar adaptada às leis naturais. Em contrapartida, a bíos está para além da mera adaptação à natureza. Bíos é a vida das relações, personalidades, valores, cultura e de tudo aquilo que é construído a partir da ética e da política. Como referido anteriormente, para Agamben a vida humana é o principal objetivo da economia teológica. Entretanto, o termo utilizado para a economia teológica é a zoé aionios, que quer dizer vida eterna. De acordo com Agamben a zoé aionios tem relação com um tipo de vida governada pela vontade divina. Inclusive a oikonomia desenvolvida pela teologia cristã a partir do quarto século estaria relacionada com a zoé aionios. Essa concepção permanece até os dias atuais.

\section{0 governo dos homens}

Em sua análise, Agamben destaca as relações entre paradigmas metafísico-teológicos e paradigmas políticos, os quais estariam interligados. Nesse momento, ele cita a fórmula de uma monarquia parlamentarista, na qual o rei reina, mas não governa. Com efeito, os negócios do reino ficariam a cargo dos ministros do rei. Essa estrutura governamental seria uma herança gnóstica na política moderna, pois 
parte de conceitos gnósticos de que o Deus bom reina, mas as forças demiúrgicas - que governam na figura dos funcionários - são más e, por isso, sempre erram. Nesse contexto político, cujo reinado e governo são constituídos de deuses "o primeiro, definido como rei, é estranho ao mundo, transcendente e totalmente inoperante; o segundo, ao contrário, é ativo e ocupa-se do governo do mundo" (AGAMBEN, 2012, p. 92).

Agamben faz essa discussão com Erik Peterson, que em seu texto Monoteísmo como problema político, afirmou que a estrutura administrativa e o aparato burocrático, pelos quais os soberanos fundamentam seu reino seriam paradigmas do governo divino no mundo. E quanto ao "governo dos homens"? Michel Foucault e principalmente Carl Schmitt viram no pastorado da Igreja Católica o paradigma daquilo que seria o moderno conceito de governo (AGAMBEN, 2012, p. 90). Schmitt analisa o modelo nacional socialista alemão e afirma que nesse Estado o povo é impolítico; fica à sombra das deliberações políticas. Enquanto que o partido e o Führer controlam, decidem mediante um paradigma pastoral-governamental.

Para Agamben existem assinaturas teológicas no Estado moderno, pois mediante os arquétipos da trindade há correspondências entre a oikonomia divina e o governo do mundo; são imaginários teológicos na constituição de modelos políticos. O filósofo italiano também discute as possibilidades de se fazer distinção entre Reino e Governo e, para isso, recorre ao tema teológico da criação. Nela a divindade cria, mas sua criação prossegue por intermédio do governo das "criaturas criadas"; há, dessa forma, uma dupla articulação entre ação divina da criação (creatio) e conservação (conservatio) (AGAMBEN, 2012, p. 107). Desse modo, quem reina nem sempre governa. Esse paradigma teológico, que se desdobra em uma dupla estrutura, é uma das bases da máquina de governos do Ocidente.

A legitimidade do soberano precisa estar constituída pela dignitas e administratio, Reino e Governo (AGAMBEN, 2012, p. 107). Entretanto, elas são separadas entre si, pois o soberano pode ocupar seu cargo, mas, não mais governar. Essa discussão também foi feita de modo mais detalhado por Agamben em seu texto O mistério do Mal (2015), no qual discute as temáticas da legitimidade e legalidade a partir da renúncia de Bento XVI. Para o filósofo italiano, governos na contemporaneidade, 
embora estejam salvaguardados pelo aparato e ordenamento jurídico, tem tido sua legitimidade questionada; e afirma que

se é tão profunda e grave a crise que nossa sociedade está atravessando, é porque ela não só questiona a legalidade das instituições, mas também sua legitimidade; não só, como se repete muito frequentemente, as regras e as modalidades do exercício do poder, mas o próprio princípio que o fundamenta e o legitima (AGAMBEN, 2015, p. 10).

\section{A economia das almas}

Giorgio Agamben lembra em seu texto O Reino e a Glória que, na década de 1970, Michel Foucault havia ministrado no Collège de França um curso em que tratou sobre a genealogia da "governamentalidade" moderna (AGAMBEN, 2012, p. 125). Foucault analisou três modalidades a partir das relações de poder: (i) o sistema legal, que é constituído pelo aparato normativo que se pode e não pode fazer; (ii) os mecanismos de punição como as penitenciárias; (iii) e por fim, aquilo que chamou de governo dos homens (FOUCAULT, 2008). Para o filósofo francês a genealogia das modernas técnicas governamentais está no pastorado cristão, de modo que o "cuidado das almas" estaria na matriz do governo político. Nesse contexto, o Estado Moderno é ao mesmo tempo individualizante e totalizante, pois cabe a ele cuidar de todas as pessoas, mas de maneira singular e individual. O pastorado enquanto "economia das almas" seria um dos propósitos centrais dos governos, logo "pastorado eclesiástico e governo político situam-se ambos no interior de um paradigma essencialmente econômico" (AGAMBEN, 2012, p. 126).

Este paradigma teológico-econômico do Estado moderno teria na crença da providência divina sua origem, na medida em que Deus se ocuparia das coisas humanas; a divindade estaria sempre a prestar atendimento a cada indivíduo e fundamentaria a concepção teológica do governo providencial no mundo. No contexto dessa máquina providencial há dois poderes distintos, mas harmônicos entre si: um poder de deliberação racional e outro de execução, sendo que esse último seria exercido pelos "ministros" ou mediadores. Agamben recorre a Tomás de Aquino para 
quem "no que concerne à racionalidade, Deus governa imediatamente todas as coisas; no que concerne, por sua vez; à execução do governo, Deus governa algumas coisas mediante outras" (AGAMBEN, 2012, p. 151). A divisão de poderes do Estado moderno tem nesse paradigma teológico seu principal arquétipo. Desse modo, há uma correlação analógica entre o governo divino no mundo e o governo profano das cidades e, a vocação econômico-governamental das democracias modernas tem nessa concepção teológica a sua origem.

\section{0 paradigma pastoral-cristão na constituição da biopolítica}

Há importantes estudos sobre biopolítica, dentre os quais destacamos os de Michel Foucault: Vigiar e punir: nascimento da prisão (1975); História da sexualidade: a vontade de saber (1976); Segurança, território e população (1977-1978) e Microfísica do poder (1979). Outro importante referencial teórico em nosso projeto são os textos do filósofo italiano Giorgio Agamben: Homo Sacer: O poder soberano e a vida nua (2010); O Estado de exceção (2003); O que resta de Auschwitz (2008) e $O$ Reino e a Glória (2012). Ainda no que diz respeito a biopolítica, a filósofa estadunidense Judith Butler contribuirá em nossa pesquisa, principalmente a partir de Relatar a si mesmo: crítica da violência ética (2015a). No que concerne às análises sobre a biopotência dialogaremos com Michael Hardt e Antônio Negri autores de Império (2001) e Multidão: guerra e democracia na era do Império (2005) e Peter Pál Pelbart autor de Vida Capital: Ensaios de Biopolítica (2011). Dialogaremos também com os textos do italiano Sandro Chignola, alguns deles publicados em revistas especializadas, dentre os quais destacamos Sobre o dispositivo. Foucault, Agamben, Deleuze (2014) e A vida, o trabalho, a linguagem: biopolitica e biocapitalismo (2015).

O termo biopolítica é anterior a Michel Foucault. Ele foi cunhado na década de 1930 pelo cientista político sueco Rudolf Kjellén para fazer referência a "biologização" do Estado. Essa modalidade estatal pode abrir caminho para um racismo de Estado, na medida em que ele estabelece quem deve estar incluído e excluído dos processos relacionados com 
a cidadania. Nesse modelo de Estado a vida é controlada, e isso incluiu àquelas que ainda se encontram na condição fetal, pois

a gravidez se torna um período para controlar e otimizar a população ainda antes do nascimento e a biopolítica, governando o desejo e o corpo da mãe, neste meio tempo, sujeitos ambos a poderes pastorais de cura e de responsabilização, inclui ainda o nascituro considerado como feto (CHIGNOLA, 2015, p. 8).

O poder, enquanto intencionalidade e instância de circulação, permite a instauração de proposições morais e filosóficas de controle. $\mathrm{Na}$ modernidade as instituições usam dispositivos legais em seus projetos de disciplina, nas relações de força e nas estratégias de poder. Nesse contexto, a vida está vinculada de maneira integral a mecanismos de modelação da existência, controle e permanente monitoramento. Um dos muitos desdobramentos disso é que a subjetividade foi reduzida ao corpo, com um predomínio da dimensão corpórea na identidade; que poderíamos chamar de uma bioidentidade. Para usar uma expressão de Foucault (2002) há nos fluxos das relações políticas uma governamentalidade, que não pode ser compreendida como uma ideologia, mas, sim, com uma tecnologia de poder.

$\mathrm{Na}$ contemporaneidade existe uma aceitação social do poder disciplinador sobre os corpos, de modo que esse poder não é apenas externo, mas, também, está internalizado nos indivíduos. Logo, o referido poder não é transcendente e nem sempre repressivo, mas, sim, um poder imanente. A modernidade rompeu a lógica de que esse poder de controle dos corpos era originário da divindade, de modo que o Estado assumiu a prerrogativa da decisão sobre a vida dos indivíduos e de domínio da vida.

Neste cenário, Foucault afirma que a vida está politizada e estatizada. Em razão dessa materialidade do corpo, pode-se falar de uma performatividade do político centrado nos processos de controle do indivíduo. No que diz respeito à biopolítica, até processos biológicos como "quem nasce", "como nasce", "onde nasce" ou "quem morre" e "quando morre" são regulados mediante os aparatos jurídicos do Estado; logo são incorporadas as preocupações do poder. Para Foucault, até o fim do século 18 essas questões não eram centrais na política. De acordo com o filósofo 
francês é justamente no final do referido século que há o surgimento da biopolítica, que emerge no contexto dos países do capitalismo industrial. Desse modo, esse tipo de exercício de poder nasce a partir de aglomeração de pessoas. O crescimento demográfico acarretou tensões nessas grandes cidades e tornou-se um desafio político. Por isso, foi preciso estabelecer dispositivos de controle.

No final do século XVIII, as revoltas camponesas entraram em regressão, acalmam-se em consequência da elevação do nível de vida dos camponeses e a revolta urbana torna-se cada vez mais frequente com a formação de uma plebe em vias de se proletarizar. Daí a necessidade de um poder político capaz de esquadrinhar esta população urbana (FOUCAULT, 1979, p. 86).

Desse modo, existe uma relação entre capitalismo e o surgimento da biopolítica. Nessa nova ordem econômica, novas formas de controle social são necessárias, pois "esse biopoder, sem dúvida, foi elemento indispensável ao desenvolvimento do capitalismo, que só pode ser garantido à custa da inserção controlada dos corpos no aparelho de produção" (FOUCAULT, 1976, p. 32). Muito embora Foucault estabeleça a modernidade como o período em que a biopolítica emerge, ele reconhece que sua origem é mais antiga. Ele faz uma genealogia da biopolítica e vê no poder pastoral sua origem mais remota. $\mathrm{O}$ pastor tem responsabilidades pelo cuidado do coletivo e também de cada membro de forma individual. Portanto, para Foucault esse paradigma teológico-pastoral de cuidado do coletivo e do individual estaria na origem do Estado moderno e da biopolítica.

Agamben (2008), diferente de Foucault, não pontua o final do século 18 como o nascimento da biopolítica. Ele discute o biopoder a partir da teoria política de Aristóteles, para quem o homem, como qualquer outro ser vivo é Zoé - uma vida nua, uma mera existência biológica. Todavia, é por meio da linguagem que o homem tem uma existência política. É no uso da linguagem que o Zoé torna-se Zoé a politikon Zôon, que consiste num animal político que lhe possibilita a biopolítica (uma vida política). No contexto da modernidade caberia ao Estado a inclusão da vida biológica nas políticas públicas, tendo em vista que a pólis, como e criação racional, é teleológica, de modo que sua existência é garantir o bem viver. 
Agamben também estabelece relações epistemológicas com o pensamento político-teológico de Carl Schmitt para quem o soberano tem o poder de decisão sobre o Estado de exceção. De acordo com Agamben, o soberano também tem o poder de legislar sobre o caos social e avaliar se a vida em sociedade está dentro dos critérios de normalidade (AGAMBEN, 2010, p. 54). Enquanto detentor do poder de exclusão-inclusão, o soberano legisla sobre o caos social, identifica a vida nua e dá a ela existência política. Os indivíduos com vida nua não são cidadãos, pois foram reduzidos à mera existência biológica. São portanto, Homo Sacer (AGAMBEN, 2010, p. 78), entregues a situações de abandono. Sendo assim, para "fugir" dessa condição de abandono o indivíduo precisa se submeter ao biopoder. Essa sujeição ao Estado moderno faz com que "o soberano entre em simbiose cada vez mais íntima não só com o jurista, mas também com o médico, com o cientista, com o perito, com o sacerdote" (AGAMBEN, 2003, p. 119) e, desse modo amplie seu controle social sobre os corpos.

Nas democracias modernas, o corpo é um sujeito político, de modo que ele ganhou centralidade nesse novo contexto político-jurídico. Dessa forma, quando falamos em direitos humanos, eles estão subordinados ao Estado. A própria expressão "direitos" já remete para a dimensão de aparatos legais que normatizam políticas sobre a vida humana. Agamben tece críticas a "judicialização" da dignidade humana a partir das declarações de direitos:

Mas é chegado o momento de cessar de ver as declarações de direitos como proclamações gratuitas de valores eternos metajurídicos, que tendem (na verdade sem muito sucesso) vincular o legislador ao respeito pelos princípios éticos eternos, para então considerá-las de acordo com aquela que é a sua função histórica real na formação do moderno Estado-nação (AGAMBEN, 2012, p. 124).

Agamben parece não criticar a ideia de direitos humanos, mas sim apresenta certo excesso em atribuir ao Estado a preservação e a decisão sobre os corpos. O filósofo italiano acredita que as declarações dos direitos representaram a transição da soberania de ordem divina para a soberania nacional; a vida nua, ao nascer, passa a ser um "cidadão" e por conta disso está sujeita ao biopoder. Para Foucault, o exercício do poder moderno se 
apoia na vida enquanto "corpo-espécie", que também podemos chamar de biopoder. A primeira vez que ele usou o termo biopoder foi em História da sexualidade: a vontade de saber (1976). Nesse texto, ele questiona a ideia de repressão sexual, principalmente no século 16. Foucault também revê o papel do sexo no saber-poder moderno e quais são os dispositivos que sustentam nossos discursos sobre sexualidade humana. Ela entra na pauta dos governos sobre políticas do corpo, bem como sobre a regulação da população. A regulação da vida está na agenda do Estado moderno, de modo que ela entrou nos cálculos governamentais como possibilidades de um exercício das relações de poder.

É no capítulo 3 de Homo Sacer: O poder soberano e a vida nua que Agamben discute estudos de Michael Foucault a respeito da biopolítica. $\mathrm{Na}$ modernidade a política teria se tornado a arte de governo da vida humana. Logo, a vida natural passou a ser objeto da administração das instituições governamentais nas sociedades modernas. $\mathrm{Na}$ interlocução que Agamben faz com Foucault também discute os dispositivos do poder e como a vida natural entrou nos cálculos do Estado. O filósofo italiano também dialoga com Hannah Arendt, que além do conhecido texto As origens do totalitarismo também foi autora de um Projeto de pesquisa sobre os campos de concentração (AGAMBEN, 2003, p. 117) em que aborda a dominação total do homem, que seria um dos argumentos que atestam que a política moderna se transformou em biopolítica. A partir do diálogo com Foucault e Arendt, Agamben amplia o debate sobre a íntima simbiose da vida nua com a política moderna.

Se a defesa dos direitos humanos é também a defesa da vida, significa dizer que os direitos humanos como discurso legitima ao Estado sua forma biopolítica. A "Declaração de Direitos do Homem e do Cidadão" afirma no segundo artigo que "A finalidade de toda associação política é a conservação dos direitos naturais imprescritíveis do homem"; o que abriu o caminho para uma gestão normalizadora do Estado (BOTH, 2009, p. 143). Foucault (2008, p. 137) fez uma crítica às Constituições que receberam influência da Revolução Francesa, tendo em vista que elas servem para fundamentar a biopolítica do Estado normatizador; por isso ele insiste que a vida foi estatizada. Agamben segue o caminho semelhante de Foucault, no sentido de que as declarações dos direitos do 
homem são mecanismos que inscrevem a vida humana nas instâncias jurídico-políticas do Estado moderno. Neste contexto, a soberania do Estado-nação tem um caráter biopolítico, pois cabe a este escolher quais vidas serão cuidadas e protegidas pelas políticas públicas.

Dentro dessa lógica biopolítica - em que o Estado-nação escolhe quais vidas humanas têm direitos - favorece o surgimento de vidas nuas como os refugiados e os apátridas. Além de Agamben, a filósofa Judith Butler (2015) também percorre esse processo da biopolítica ao analisar o poder do Estado sobre os corpos. Os refugiados, por exemplo, são corpos que entram nos cálculos dos países europeus, os quais estabelecem "cotas" para os países da União Europeia. Desse modo, o Estado faz demarcações de quais vidas são "vivíveis" e quais são descartáveis. Butler faz essa discussão também a partir de certas práticas do neoimperialismo estadunidense, como, por exemplo, as práticas de tortura em Guantánamo. Ali, inclusive, é o Estado quem decide quais vidas merecem pranto e aquelas que não podem ser lamentadas. Desse modo, Butler diz que as vidas descartáveis não mereceriam pranto e luto; isso tudo determinado pelo biopoder do Estado.

Para Agamben as intersecções entre política e medicina também são instrumentalizadoras da biopolítica na modernidade e o médico torna-se um soberano sobre a vida e morte de pessoas. No governo biopolítico cabe a esse profissional de saúde decidir, por exemplo, quais pessoas devem ficar de fora por falta de vagas em uma Unidade de Terapia Intensiva. Entretanto, não é apenas questões de morte que são administradas nesse modelo de Estado, mas as relacionadas com o início da vida pois

a gravidez se torna um período para controlar e otimizar a população ainda antes do nascimento e a biopolítica, governando o desejo e o corpo da mãe, neste meio tempo, sujeitos ambos a poderes pastorais de cura e de responsabilização, inclui ainda o nascituro considerado como feto (CHIGNOLA, 2015, p. 8). 


\section{Considerações finais}

Os fundamentos e a estrutura do Estado moderno no Ocidente são compreendidos a partir de suas origens teológicas. Há um paradigma teológico-econômico do Estado moderno, de modo que sua origem estaria na crença da providência divina, na medida em que Deus se ocuparia das coisas humanas; a divindade estaria sempre a prestar atendimento a cada indivíduo e fundamentaria a concepção teológica do governo providencial no mundo. Estado e religião teriam como fim uma espécie de "função pastoral" do país, o que na conjuntura atual do Brasil pode ser evidenciado mediante projetos como o controvertido "Estatuto da Família”. Portanto, de acordo com Agamben, imaginários teológicos fundamentam principalmente as técnicas de governo do Estado moderno.

O paradigma teológico-econômico estruturou as técnicas de governo, de modo que este tem - entre suas principais finalidades garantir direitos aos cidadãos. Para garanti-los o Estado cria aparelhos disciplinares, a fim de sujeitar os indivíduos e, se preciso for, eliminar aqueles que supostamente estivessem colocando em risco a população; a morte de pobres nas periferias por policiais seria um exemplo. Tanto Agamben como Michel Foucault fizeram críticas a certos modelos de sujeição e métodos disciplinadores usados pelo Estado para legitimar a garantia dos direitos humanos. Nesse modelo, a vida dos indivíduos entra nos cálculos governamentais e mesmo na racionalidade econômica. Neste cenário, a política se tornou biopolítica, quem tem suas origens no paradigma teológico-econômico e no paradigma pastoral cristão.

$\mathrm{O}$ poder se legitima e funciona na sociedade a partir de modelos de políticas de controle e governo da vida. A partir disso, pode-se questionar também a ideia de "vida privada". Se o Estado moderno tem a incumbência de cuidar da vida, isso remete para a justificativa de que ele pode exercer influência não apenas na pólis, mas também no oikos. $\mathrm{O}$ Estado pode entrar nas casas; saber o que se passa lá e até mesmo regular como devem ser as relações vividas entre as pessoas que ali moram. Um dos muitos exemplos disso é a concepção de um Estado fiscalizador do núcleo familiar, a fim de averiguar dimensões no interior da casa como 
proteção e educação da criança, violência doméstica, entre outras. Desse modo, a vida não fica mais confinada à esfera privada.

\section{Referências}

AGAMBEN, G. O Estado de exceção. São Paulo: Boitempo, 2003.

AGAMBEN, G. O que resta de Auschwitz. São Paulo: Boitempo, 2008.

AGAMBEN, G. Homo Sacer: O poder soberano e a vida nua. Belo Horizonte: Editora UFMG, 2010.

AGAMBEN, G. O Reino e a Glória. São Paulo: Boitempo Editorial, 2012.

AGAMBEN, G. O mistério do mal. São Paulo: Boitempo Editorial, 2015.

ARENDT, H. A condição humana. Rio de Janeiro: Forense Universitária, 2007.

ARENDT, H. Origens do totalitarismo: antissemitismo, imperialismo, totalitarismo. São Paulo: Cia das Letras, 2007.

BENJAMIN, W. O capitalismo como religião. São Paulo: Boitempo Editorial, 2013.

BOTH, V. Biopoder e direitos humanos: estudos a partir de Michel Foucault. Passo Fundo: IBIFE, 2009.

BUTLER, J. Relatar a si mesmo: crítica da violência ética. Belo Horizonte: Autêntica, 2015a.

BUTLER, J. Quadros de guerra: quando a vida é passível de luto? Rio de Janeiro: Civilização Brasileira, 2015b.

CATROGA, F. Entre Deuses e Césares. Secularização, laicidade e religião civil: uma perspectiva histórica. Coimbra: Almedina, 2006.

CHIGNOLA, S. Sobre o dispositivo. Foucault, Agamben, Deleuze. Cadernos IHU Ideias, ano 12, 2014, v. 12: 3-18.

CHIGNOLA, S. A vida, o trabalho, a linguagem: biopolítica e biocapitalismo. Cadernos IHU, ano 13, 228, v. 13, 2015. 
FOUCAULT, M. Vigiar e punir: nascimento da prisão. Petrópolis: Vozes, 1975.

FOUCAULT, M. História da sexualidade: a vontade de saber. Rio de Janeiro: Graal, 1976.

FOUCAULT, M. Microfísica do poder. Rio de Janeiro: Graal, 1979.

FOUCAULT, M. Segurança, território e população. Curso no Collège de France (1977-1978). São Paulo: Martins Fontes, 2008.

HARDT, M.; NEGRI, A. Império. Rio de Janeiro: Record, 2001.

HARDT, M.; NEGRI, A. Multidão: guerra e democracia na era do Império. Rio de Janeiro, Record, 2005.

HINKELAMMERT, F. A maldição que pesa sobre a lei: as raízes do pensamento crítico em Paulo de Tarso. São Paulo: Paulus, 2012.

PELBART, P. P. Vida Capital: Ensaios de Biopolítica. São Paulo: Iluminuras, 2011.

ROSSEAU, J.-J. Do contrato social. São Paulo: Saraiva, 2011.

RUIZ, C. B. Giorgio Agamben, genealogia teológica da economia e do governo. São Leopoldo: Cadernos IHU em Formação, 2015.

Recebido: 27/11/2018

Received: 11/27/2018

Aprovado: 25/04/2019

Approved: 04/25/2019 